\title{
QUE PLANTA TE IMPORTA? UM RELATO DE CASO SOBRE O SIGNIFICADO DAS PLANTAS PARA AS PESSOAS
}

\section{WHICH PLANT MATTERS TO YOU? A CASE REPORT ON THE MEANING OF PLANTS FOR PEOPLE}

\author{
Ana Boeira PORTO ${ }^{1}$; Valmir Luiz BITTENCOURT ${ }^{1}$; Filipe Ferreira da SILVEIRA ${ }^{1}$; Tatiana Mota \\ MIRANDA $^{2}$
}

\begin{abstract}
${ }^{1}$ Universidade Federal do Rio Grande do Sul - UFRGS, Programa de Pós-graduação em Botânica, Laboratório de Estudos em Vegetação Campestre - LEVCamp, Porto Alegre, Rio Grande do Sul, Brasil.

${ }^{2}$ Universidade Federal do Rio Grande do Sul - UFRGS, Programa de Pós-graduação em Desenvolvimento Rural, Porto Alegre, Rio Grande do Sul, Brasil.*aanaporto@gmail.com
\end{abstract}

\section{RESUMO}

Apresentamos neste trabalho um relato de caso sobre a análise de uma pesquisa exploratória desenvolvida no contexto de uma disciplina de Etnobotânica inserida no Programa de PósGraduação em Botânica da Universidade Federal do Rio Grande do Sul. O objetivo do relato é instigar e discutir a relação existente entre seres humanos e plantas, a partir da investigação narrativa dos sujeitos. Partindo da perspectiva etnobotânica, apoiados nos estudos das interações simbólicas e culturais que esta ciência proporciona, analisamos as respostas de um grupo de 30 pessoas à seguinte pergunta: "qual a primeira planta que vem à tua cabeça quando te pergunto: me diz uma planta importante para ti e por quê?". As espécies citadas foram classificadas em nativas ou exóticas. As justificativas dadas pelos entrevistados para a escolha das espécies citadas apresentaram um padrão que categorizamos em: Afetivo, Espiritual, Ecológico e Utilitário. O valor Utilitário dominou as respostas, seguido do valor Afetivo. As plantas apresentaram significados únicos para cada sujeito analisado e, por vezes, esses significados e justificativas para suas escolhas os conectam profundamente com seu senso de identidade. Conceitos como memória botânica e cegueira botânica estão envolvidos na compreensão acerca das percepções desses sujeitos com relação às plantas citadas. Apenas 7,7\% das espécies citadas são nativas do estado do Rio Grande do Sul. O baixo número de espécies nativas citadas é visto por nós como um resultado histórico e cultural.

PALAVRAS-CHAVE: Espécies exóticas, Etnobotânica urbana, Investigação narrativa, memória botânica

\begin{abstract}
In this work, we present a case report on the analysis of exploratory research developed in the context of an Ethnobotany discipline inserted in the Postgraduate Program in Botany at the Federal University of Rio Grande do Sul. The purpose of the report is to instigate and discuss the relationship between human beings and plants, based on the subjects' narrative investigation. From the ethnobotanical perspective, supported by the studies of symbolic and cultural interactions that this science provides, we analyzed the responses of a group of 30 people to the following question: "what is the first plant that comes to your mind when I ask you: tell me a plant important to you and why?". The species mentioned were classified as native or exotic. The justifications given by the interviewees for the choice of the mentioned species presented a pattern. Thus, we categorized them into the following groups: Affective, Spiritual, Ecological and Utilitarian. The Utilitarian value
\end{abstract}


PORTO, A.B. et al. Que planta te importa? Um relato de caso sobre o significado das plantas para as pessoas. Ethnoscientia, v.6, n.1, 2021. D.O.I.: 10.18542/ethnoscientia.v6i1.10467

dominated the responses, followed by the Affective value. The plants presented unique meanings for each analyzed subject and, sometimes, these meanings and justifications for their choices connect them deeply with their sense of identity. Concepts such as Botanical Memory and Botanical Blindness are involved in understanding the perceptions given by the subjects in relation to the plants mentioned. Only $7.7 \%$ of the species mentioned are native to the state of Rio Grande do Sul. The low number of native species mentioned is seen by us as a historical and cultural result.

KEYWORDS: Exotic species, Urban ethnobotany, Narrative investigation, Botanical Memory

\section{INTRODUÇÃO}

O conceito de natureza e sua valoração tem passado por profundas transformações com a urbanização das sociedades nos últimos séculos, o que gerou afastamento e desconexão das pessoas com os processos naturais, fenômeno acentuado pelos avanços tecnológicos recentes (SALATINO, 2001). Em resposta a esse afastamento, observamos o surgimento das áreas verdes nas cidades e o cultivo de plantas nos quintais para fins não apenas utilitaristas, mas também estéticos, ou seja, para a promoção do bem-estar. Esse movimento acarreta a ressignificação dos jardins, que desde a antiguidade vêm sendo usados como símbolo de status através do domínio sobre a natureza, e passam agora a representar tanto o contato com o meio natural quanto uma forma de expressão da personalidade (BHATTI et al., 2009; NASSAUER, 1988).

A influência da vegetação no bem-estar das pessoas tem sido alvo de pesquisas em diversas áreas. Ulrich (1984) observou uma melhor recuperação de pacientes hospitalares cujos quartos tinham vista para áreas verdes, em comparação aos pacientes cuja vista era um muro. Segundo Kaplan (1992), o simples fato de saber que há um parque nas redondezas torna um bairro mais valorizado e aumenta o grau de satisfação dos moradores, independentemente de eles usarem ou não aquele espaço. A autora também informa que a interação com a paisagem varia significativamente com a idade das pessoas, sendo especialmente relevante para crianças. Como destacado por Ryan (2012), as memórias constituídas na infância permanecem por toda a vida e incluem uma riqueza de detalhes sensoriais que vão muito além da visão, sentido do qual passamos a depender majoritariamente. Há um senso de experimentação na forma como as crianças interagem com a natureza, de descoberta. As memórias constituídas nessa fase carregam consigo uma grande carga de afeto, gerando mais tarde na vida o desejo de retorno a esse espaço, esse contexto de deslumbramento e poucas preocupações que é próprio da infância.

Os benefícios da vegetação em áreas urbanas vão além do valor estético mencionado acima. Melhora na qualidade do ar pelo aumento da umidade e captação de 
PORTO, A.B. et al. Que planta te importa? Um relato de caso sobre o significado das plantas para as pessoas. Ethnoscientia, v.6, n.1, 2021. D.O.I.: 10.18542/ethnoscientia.v6i1.10467

poluentes, redução das ilhas de calor e da poluição sonora, abrigo e alimento para a fauna e maior eficiência na drenagem da água das chuvas são alguns benefícios ambientais da vegetação às cidades. $\mathrm{O}$ cultivo de plantas nativas ainda tem benefícios adicionais, não apenas por sua rusticidade e para reduzir os riscos de invasão biológica, mas para valorizar as paisagens locais e aproximar as pessoas da biodiversidade de cada região (HEIDEN et al., 2009).

No entanto, a composição de espécies cultivadas em determinada região não depende apenas de questões ambientais, mas também de questões culturais. Comumente, populações humanas levam consigo espécies de plantas em suas migrações, por questões econômicas, de sobrevivência, mas também de afeto, desenvolvendo durante milênios um trabalho de dispersão e seleção de variedades cultivadas. Como resultado, atualmente no Brasil, as plantas comercializadas em larga escala são principalmente espécies exóticas (HEIDEN et al., 2009). Esse comportamento traz consigo uma ameaça significativa à conservação da biodiversidade: o risco de invasões biológicas. Segundo Ziller (2001), as plantas invasoras são a segunda maior causa da perda de biodiversidade no mundo, perdendo apenas para a destruição de hábitats. Algumas espécies são cultivadas há tanto tempo e se adaptaram tão bem a ponto de terem se tornado espontâneas ou naturalizadas, como é o caso da goiabeira (Psidium guajava L.), que poucas pessoas saberiam dizer que não é nativa no Sul do Brasil.

Para entender as motivações que conectam as pessoas às plantas, motivações muitas vezes subjetivas e não-quantificáveis, podemos nos valer do olhar da Etnobotânica, uma ciência que busca entender essas relações e suas minúcias. A classificação das plantas cultivadas em categorias de uso é uma das formas de entendermos as motivações dos sujeitos, sendo uma prática comum a vários trabalhos recentes (ALBUQUERQUE et al., 2007; MIRANDA e HANAZAKI, 2008; EICHEMBERG et al., 2009; LEITÃO et al., 2009; PRADO et al., 2019).

Dessa forma, o objetivo geral deste trabalho é instigar e discutir a relação existente entre seres humanos e plantas, a partir da investigação narrativa dos sujeitos, acerca das importâncias e significados que as pessoas atribuem às plantas. Para isso, nos debruçamos sobre as justificativas dadas pelos entrevistados e entrevistadas com relação ao porque da escolha da planta citada. Esta pesquisa exploratória foi oportunizada no contexto da disciplina de Etnobotânica, inserida no Programa de Pós-graduação em Botânica da Universidade Federal do Rio Grande do Sul (UFRGS). 
PORTO, A.B. et al. Que planta te importa? Um relato de caso sobre o significado das plantas para as pessoas. Ethnoscientia, v.6, n.1, 2021. D.O.I.: 10.18542/ethnoscientia.v6i1.10467

\section{MATERIAL E MÉTODO}

O presente trabalho se caracteriza como uma pesquisa qualitativa (YIN, 2016), sendo a coleta de dados realizada através do emprego de entrevista semiestruturada (ALEXIADES, 1996) iniciada com a seguinte questão: “Qual a primeira planta que vem na tua cabeça quando eu te peço: me diz uma planta importante para ti e o porquê”. As pessoas entrevistadas responderam, ainda, sobre seu sexo, idade e nível de escolaridade. A coleta de dados foi realizada por meio de aplicativo de mensagens (Whatsapp) em junho de 2020. É necessário pontuar que este trabalho foi desenvolvido durante uma quarentena ocasionada pela pandemia de COVID-19 iniciada no ano corrente ao da pesquisa. Assim, as relações interpessoais, de modo geral, foram fortemente mantidas por aplicativos de comunicação. Nesse sentido, o questionamento foi enviado aos contatos mais recentes da primeira autora, sendo o grupo amostral constituído por 34 pessoas residentes em zonas urbanas localizadas nos estados do Rio Grande do Sul, Paraná e Rio de Janeiro. Como a presente pesquisa é pontual, não compõe um projeto de pesquisa maior e não inclui integrantes de comunidades tradicionais, a mesma não se enquadrou nos parâmetros para inclusão no Comitê de Ética. Ressaltamos que todos os participantes da pesquisa são maiores de 18 anos e concordaram com a utilização, análise e publicação dos dados através do assentimento, por meio digital, de um Termo de Consentimento Livre Esclarecido.

A nomenclatura botânica foi atualizada através de consulta à base de dados Tropicos@ (Tropicos 2020). Pelo fato de a pesquisa ter sido realizada a distância, a citação da planta pelos interlocutores não foi seguida de coleta ou apresentação direta da espécie aos pesquisadores. Assim, a identificação em nível de espécie foi possível somente para as respostas nas quais os entrevistados assim as citaram, como Epipremnum aureum (Linden \& André) G.S. Bunting, Paspalum notatum Flüggé e Cola acuminata (P. Beauv.) Schott \& Endl (Tabela 1).

Para a categorização em exótica ou nativa, nós assumimos o Rio Grande do Sul como referencial biogeográfico e utilizamos a definição de Richardson e colaboradores (2000). Para realizar a análise das justificativas, utilizamos a investigação narrativa dos sujeitos (CLANDININ e CONNELLY, 2012). Os dados foram igualmente analisados por meio de estatísticas descritivas, como totalização de usos (SILVA et al., 2010).

Assim como em diversos trabalhos etnobotânicos (ALBUQUERQUE et al., 2007; MIRANDA e HANAZAKI, 2008; EICHEMBERG et al., 2009; LEITÃO et al., 2009; PRADO et al., 2019), as respostas foram categorizadas a posteriori conforme os significados e utilizações atribuídos às plantas em quatro categorias de valor: Afetivo, 
PORTO, A.B. et al. Que planta te importa? Um relato de caso sobre o significado das plantas para as pessoas. Ethnoscientia, v.6, n.1, 2021. D.O.I.: 10.18542/ethnoscientia.v6i1.10467

Espiritual, Ecológico e Utilitário, sendo esta última subdividida em Alimentícia, Medicinal e Ornamental. Com base no uso de algumas palavras e expressões utilizadas pelos entrevistados, as quais forneceram evidências das formas como eles atribuem os valores e significados às plantas, categorizamos as respostas em: (1) Afetivo: referências à infância, uso do diminutivo (plantinhas, florzinhas); verbos como amar, adorar; qualificação da planta como algo de valor, sem justificativa; (2) Espiritual: uso de termos relacionados à força, poder, energia, proteção, bem-estar; (3) Ecológico: menção a características da planta que beneficiam a sociedade como um todo ou o ambiente; (4) Utilitário - (a) Uso Medicinal: chá; (b) Uso Alimentício: frutas, árvores frutíferas, temperos e (c) Uso Ornamental: comentários envolvendo beleza ou a facilidade de cultivo.

\section{RESULTADOS E DISCUSSÃO}

Do total de 34 entrevistas previstas na amostragem, foram obtidas 30 respostas, sendo de 22 mulheres e oito homens com idades entre 21 e 73 anos. Do total, 20 pessoas possuem ensino superior completo, sendo oito delas formadas em Ciências Biológicas.

Foram citadas 26 plantas ou agrupamentos de plantas (Tabela 1), pois em alguns momentos obtivemos respostas em nível de espécie como Paspalum notatum; outras em nível de gênero, como "[...] as espécies do gênero Hypericum [...]”; e algumas citações de um agrupamento específico, como “[...] medicinais [...]”, “[...] cactus [...]” e "[...] acho que não me vem nenhuma planta em específico. Vem todo o conjunto "Pampa” [...]".

Tabela 1: Relação de plantas levantadas na entrevista semiestruturada realizada com 30 pessoas. Resultados ordenados por categoria de resposta.

\begin{tabular}{ccccc}
\hline Família & Nome popular & Gênero / & Origem & Categoria (\%) \\
\hline Apocynaceae & coração-de-mãe & Ceropegia & África & Afetivo (26,7) \\
Gesneriaceae & violeta & Streptocarpus & África & \\
Lamiaceae & alecrim & Salvia & Europa & \\
Rutaceae & limoeiro & Citrus & Ásia & \\
Solanaceae & petúnia & Petunia & Nativa & \\
Araceae & jiboia & Epipremnum aureum & Oceania & \\
Rutaceae & bergamota & Citrus & Ásia & \\
Myrtaceae & goiabeira & Psidium & América & \\
Hypericaceae & Espécies do gênero Hypericum & Hypericum & Nativa & Ecológico $(16,7)$ \\
- & medicinais & - & - & \\
Poaceae & grama-forquilha & Paspalum notatum & Nativa & \\
- & grama & - & - & \\
- & Espécies do bioma Pampa & Nativa & \\
Asteraceae & girassol & Helianthus & América & Espiritual $(13,3)$ \\
Malvaceae & obi (semente de cola) & Cola acuminata & África &
\end{tabular}


PORTO, A.B. et al. Que planta te importa? Um relato de caso sobre o significado das plantas para as pessoas. Ethnoscientia, v.6, n.1, 2021. D.O.I.: 10.18542/ethnoscientia.v6i1.10467

\begin{tabular}{|c|c|c|c|}
\hline Asparagaceae & espada-de-são-jorge* & Dracaena & África \\
\hline Malpighiaceae & acerola & Malpighia & América Alimentício $(13,3)$ \\
\hline Apiaceae & salsa & Petroselinum & América \\
\hline Euphorbiaceae & aipim & Manihot & América \\
\hline Poaceae & cevada & Hordeum & Ásia \\
\hline Lamiaceae & lavanda & Lavandula & Medicinal $(23,3)$ \\
\hline Asteraceae & camomila* & Matricaria & Ásia \\
\hline Plantaginaceae & tansagem & Plantago & Nativa \\
\hline Verbenaceae & erva-luisa & Aloysia & América \\
\hline Xanthorrhoeaceae & babosa & Aloe & África \\
\hline
\end{tabular}

*Espécies citadas mais de uma vez, sendo: três citações para camomila e duas para espada-de-são-jorge e cactus.

As plantas classificadas como de valor Utilitário dominaram com um total de 43,3\% das citações, seguidas pela categoria de valor Afetivo. Vários entrevistados que tiveram suas respostas categorizadas em Afetivo compartilharam a utilização da palavra infância e verbos como amo e/ou adoro em suas justificativas: "Quando me perguntam isso, sempre vem à minha cabeça a goiabeira, é uma árvore da minha infância [...]"; "Violeta, porque minha mãe ama [...]"; "Alecrim, porque eu amo o cheiro e as flores roxinhas". Alguns deles utilizaram o grau diminutivo para se referir e caracterizar a planta citada: " [...] foi a primeira plantinha que plantei com minha vó [...]". Fica evidente a atribuição de valor sentimental às plantas e as palavras utilizadas demonstram também que o questionamento suscitou memórias afetivas. Neste sentido, Ryan (2012) discorre em seu trabalho sobre o conceito denominado por ele como memória botânica. Este termo se refere ao fato de as plantas estarem intimamente conectadas aos aspectos sensoriais e emocionais das memórias humanas. $\mathrm{O}$ autor menciona que, na infância, formamos memórias com maior participação dos outros sentidos além da visão, sendo muito comum que as plantas do entorno, com seus cheiros, texturas e sabores despertem a atenção da criança e permaneçam até a idade adulta.

No campo do emocional podemos perceber que, em alguns casos, as plantas ganham significados subjetivos, como declara este entrevistado: "Petúnia. Não sou conhecedor de plantas. É bem provável que se eu estivesse de frente para uma petúnia nem soubesse reconhecê-la, mas seus significados estão para além da botânica. Acho que a magia do significado é que uma coisa pode transformar-se em diversas outras coisas e ganhar tantos outros sentidos através dos olhos daqueles que as significam. Isso permite, por exemplo, que petúnias sejam importantes para mim mesmo que eu as desconheça". Assim, a memória botânica nos leva a perceber que, para cada ser humano, a representação e o significado das plantas serão únicos devido às subjetividades intrínsecas dos sujeitos. 
PORTO, A.B. et al. Que planta te importa? Um relato de caso sobre o significado das plantas para as pessoas. Ethnoscientia, v.6, n.1, 2021. D.O.I.: 10.18542/ethnoscientia.v6i1.10467

Em várias respostas é possível identificar a motivação afetiva, ainda que não de forma explícita, como no caso da entrevistada que cita a camomila como medicinal por influência de experiências afetivas que teve com sua avó, o que caracteriza um utilitarismo relacionado ao contato prévio afetivo, desencadeando memórias carinhosas de momentos que já se foram. Uma das entrevistadas, bióloga, cita Paspalum notatum por ser a primeira planta que aprendeu a identificar. $O$ fato de ser a sua primeira identificação confere o caráter afetivo à planta, embora a entrevistada também faça referência à importância de conhecer as variações morfológicas da espécie, devido à alta frequência desta nos campos do bioma Pampa. A entrevistada acaba concluindo que a importância desta planta se relaciona à sua difícil identificação, o que apresenta relação direta com a superação de desafios pelos quais passou ao longo de sua carreira.

A citação de plantas com viés esotérico, categorizadas como de valor Espiritual, de modo geral, estão relacionadas às crenças e religiões. A espada-de-são-jorge, por exemplo, citada por dois participantes, é encontrada em diversos quintais do Brasil. A justificativa se faz como proteção espiritual, pois em rituais de religiões de matriz africana esta planta é utilizada principalmente para afugentar as energias negativas das pessoas e dos locais (ALVES et al., 2019). A citação do girassol foi trazida pela entrevistada como uma forma de ressignificação: “Girassol, por me lembrar renovação, mudanças, fases". Houve, neste caso, a transmutação do campo concreto do que é um girassol propriamente dito para a abstração do que a planta (girassol) passou a ser para este indivíduo. Dada a fisiologia acerca do ciclo de vida do girassol, em analogia com as fases da vida humana, podemos perceber que esta planta instiga a ressignificação de momentos que a entrevistada viveu.

$\mathrm{Na}$ categoria valor Ecológico incluímos as citações em que os interlocutores destacam o valor da planta para a sociedade como um todo ou para o ambiente e não apenas para si mesmos. Nesse contexto, três das citações são atribuídas a biólogas que não conseguem apontar apenas uma espécie de importância destacada, mas sim conjuntos de espécies reunidos por um bioma, o Pampa, o gênero, nesse caso, Hypericum, sendo esta última situação fundamentada em uma percepção acerca do complexo realístico: “[...] Para mim, essas espécies me fazem pensar que nada é tão simples quanto aparenta ser [...] dependendo do lugar do mundo que tu estiver, essas espécies serão vistas com um olhar bem distinto. Na Europa, é remédio, é vida, é importante. Nos Andes representa a paisagem, biodiversidade, natureza - sempre vista e lembrada por todos. Aqui no sul do Brasil, Uruguai, Argentina são insignificantes aos olhos do leigo (maioria das pessoas). Em resumo, me faz pensar na visão utilitarista doentia do homem sobre a natureza [...]". 
PORTO, A.B. et al. Que planta te importa? Um relato de caso sobre o significado das plantas para as pessoas. Ethnoscientia, v.6, n.1, 2021. D.O.I.: 10.18542/ethnoscientia.v6i1.10467

Ela ainda complementa que "[...] se eu não falasse em Hypericum, provavelmente seria uma frutifera que me levasse a memórias da minha infância", o que mais uma vez, nos remete à memória botânica.

A terceira entrevistada confessa que não consegue pensar em uma planta em específico: "Nesse momento, vejo as medicinais como fundamentais, aqui em casa tem sido [...] e no mais, as plantas são importantes pra mim, se é pra falar assim, porque elas realizam a fotossíntese, capturando o $\mathrm{CO}_{2}$ disponível na atmosfera e devolvendo $\mathrm{O}_{2}[\ldots]$ eu não consigo pensar em uma só.”. O mais instigante nessas respostas é a relutância das entrevistadas em elencar uma única espécie, o que pode ter origem no próprio pensamento ecológico, pelo qual não faz sentido pensar uma espécie separada de seu meio (ODUM E BARRETT, 2008).

Kaplan (1992) destaca que especialistas cujo trabalho envolve plantas desenvolvem um "olho treinado" para determinados grupos vegetais ou padrões vegetacionais que podem diferir bastante das preferências estéticas do público leigo. Eaton (1988), Fudge (2001) e Rolston (2002) dissertam sobre como a experiência estética é dependente de diversos fatores, incluindo as propriedades estéticas do objeto (no caso, planta), mas também do conhecimento do sujeito sobre tal objeto. Ou seja, a beleza está parcialmente nas características do objeto, mas também depende do conhecimento de quem o vê. Considerando que o grupo amostrado inclui interlocutoras com formação em Ciências Biológicas, é natural que sejam atribuídos valores às plantas devido a características que não são evidentes para boa parte da população. Naturalmente, respostas como estas são difíceis de classificar, embora seja evidente a presença de elementos de afetividade e de questões utilitárias em seus conteúdos, o que reforça a compreensão dos múltiplos significados que uma mesma planta pode apresentar.

O aspecto utilitário presente na relação plantas-seres humanos está frequentemente presente em pesquisas etnobotânicas (ALBUQUERQUE et al., 2007; EICHEMBERG et al., 2009; MIRANDA e HANAZAKI, 2008; LEITÃO et al., 2009; PRADO et al., 2019) e, nos dados da presente pesquisa, as respostas desta categoria se caracterizam como tal entre os Usos Medicinal, Alimentício e Ornamental. Aliada a esta categoria está a origem das plantas, visto que em sua maioria $(92,3 \%)$ as espécies desta categorização são exóticas e apenas $7,7 \%$ das espécies citadas são nativas. Embora o destaque na menção de espécies ornamentais e exóticas seja um fato comumente reportado em pesquisas etnobotânicas desenvolvidas em áreas urbanas (MIRANDA et al., 2007; EICHEMBERG et al., 2009), os motivos para o alto número de espécies exóticas citadas podem ser muitos e variam desde a 
PORTO, A.B. et al. Que planta te importa? Um relato de caso sobre o significado das plantas para as pessoas. Ethnoscientia, v.6, n.1, 2021. D.O.I.: 10.18542/ethnoscientia.v6i1.10467

marginalização e apagamento histórico dos povos indígenas nativos, detentores de conhecimentos tradicionais da terra (MOREIRA, 2001); os impactos das culturas italianas e germânicas advindas de processos migratórios trazendo pessoas e com elas espécies vegetais de suas regiões que acabam por encontrar no Rio Grande do Sul um clima semelhante ao da Europa, especialmente na região da Serra (BUBLITZ, 2011); a dificuldade de encontrar espécies nativas nos grandes centros de varejo de plantas de interesse econômico ou o simples fato do contato com a natureza estar cada vez mais restrito a áreas pequenas, altamente antropizadas em nossa sociedade. A cegueira botânica (SALATINO E BUCKRIDGE, 2016) pode endossar a compreensão acerca deste resultado, porque de maneira geral os seres humanos têm uma dificuldade fisiológica em reconhecer as plantas frente a animais. Este fato é agravado por fatores sociais e culturais que desvalorizam o saber botânico e descaracterizam a presença das plantas e da natureza no cotidiano humano (SALATINO, 2001).

\section{CONSIDERAÇÕES FINAIS}

Os dados coligidos, apesar de exploratórios, apontam que são variados os significados atribuídos à importância das plantas para os sujeitos desta pesquisa e que são diversos os motivos que fazem com as pessoas se lembrem de uma ou outra planta em particular. As motivações evidenciam aspectos relacionados mais diretamente às funções específicas que lhes são atribuídas, seja para um indivíduo ou para um ecossistema. Por outro lado, razões espirituais e afetivas adentram um contexto muito mais subjetivo e complexo, ligado à relação de pertencimento que desenvolvemos com os grupos com que nos relacionamos, o que é explicado pelo conceito de memória botânica.

Conforme demais pesquisas etnobotânicas mencionadas ao longo do texto, os dados coletados no presente trabalho apontam ainda que, para o contexto de estudos com populações urbanas, as plantas exóticas e ornamentais são as mais usualmente mencionadas. Este fato pode ser atribuído a fatores associados aos aspectos culturais, à disponibilidade das plantas no contexto de cada indivíduo ou mesmo ao desconhecimento das espécies nativas.

Apesar da pontualidade da presente investigação, chamamos atenção de outros pesquisadores e pesquisadoras para a relação cercada de significado existente entre os seres humanos e as plantas. Ressignificar os elementos naturais pode auxiliar na diminuição da lacuna que se criou entre o ser humano e a natureza. Através de trabalhos que suscitem a sensibilização, como o questionamento abordado por nós, as pesquisas com este tema 
PORTO, A.B. et al. Que planta te importa? Um relato de caso sobre o significado das plantas para as pessoas. Ethnoscientia, v.6, n.1, 2021. D.O.I.: 10.18542/ethnoscientia.v6i1.10467

podem contribuir para que as pessoas percebam os diversos significados e importâncias que as plantas têm para os indivíduos e para o funcionamento da biosfera como um todo.

\section{AGRADECIMENTOS}

As autoras e autores agradecem à Coordenação de Aperfeiçoamento de Pessoal de Nível Superior - Brasil (CAPES) pela concessão de bolsas de doutorado e mestrado aos três primeiros pesquisadores (Código de financiamento 001) e pela bolsa PNPD para a última autora.

\section{REFERÊNCIAS BIBLIOGRÁFICAS}

ALBUQUeRQUE, U. P.; MONTEIRO, J. M.; RAMOS, M. A.; AMORIM, E. L. C. Medicinal and magic plants from a plubic market in northeastern Brazil. Journal of EthnoPharmacology, v. 110, p. 76-91, 2007.

ALEXIADES, M. N. An introduction to basic concepts and techniques. In: ALEXIADES, M. N. Selected Guidelines for Ethnobotanical Research: A Field Manual. New York: New York Botanical Garden, 1996. p. 53-94.

ALVES, K. C. H.; POVH, J. A.; PORTUGUEZ, A. P. Etnobotânica de plantas ritualísticas na prática religiosa de matriz africana no município de Ituiutaba, Minas Gerais. Ethnoscientia, v. 4, n. 1, 2019. Disponível em: <10.22276/ethnoscientia.v4i1.239>. Acesso em: 25 ago 2020.

BUBLITZ, J. História ambiental da colonização alemã no Rio Grande do Sul: o avanço na mata, o significado da floresta e as mudanças no ecossistema. Tempos Históricos, v. 15, p. 239-267, 2011.

CLANDININ, J. D.; CONNELLY, M. F. Pesquisa narrativa: experiência e história em pesquisa qualitativa. Revista de Educação Pública, v. 21, n. 47, p. 663-667, 2012.

EATON, M. M. Fact and Fiction in the Aesthetic Appreciation of Nature. The Journal of Aesthetics and Art Criticism, v. 56, n. 2, p. 149-56, 1998. Disponível em: $<10.2307 / 432253>$. Acesso em: 25 ago 2020.

EICHEMBERG, M. T.; AMOROZO, M. C. M.; MOURA, L. C. Composição de espécies e uso de plantas em quintais urbanos antigos de Rio Claro, Sudeste do Brasil. Acta Botanica Brasilica, v. 23, 2009. Disponível em: < https://doi.org/10.1590/S010233062009000400016>. Acesso em: 30 set 2020.

FUDGE, R.S. Imagination and the Science-Based Aesthetic Appreciation of Unscenic Nature. The Journal of Aesthetics and Art Criticism, v. 59, p. 275-285, 2001. Disponível em: $<10.1111 / 1540-6245.00025>$. Acesso em: 25 ago 2020.

HEIDEN, G.; STUMPF, E.R.T.; IGANCI, J.R.V.; CORRÊA, L.B; PERLEBERG, T.D.; ROMANO, C.M.; BARBIERI, R.L. Plantas ornamentais nativas. In: STUMPF, E.R.T.; 
BARBIERI, R.L.; HEIDEN, G. (Org). Cores e formas no Bioma Pampa - plantas ornamentais nativas. Pelotas: Embrapa Clima Temperado, 2009. p. 50-253.

KAPLAN, R. The Psychological Benefits of Nearby Nature. In: RELD, D. The Role of the Horticulture in Human and Social Development. Arlington: Timber Press, 1992. Vol. 6, p. $125-136$.

LEITÃO F.; FONSECA-KRUEL, V. S.; SILVA, I. M.; REINERT, F. Urban ethnobotany in Petrópolis and Nova Friburgo (Rio de Janeiro, Brazil). Brazilian Journal of Pharmacognosy, v. 19, p. 333-342, 2009.

MIRANDA, T. M.; AMOROZO, M. C. M.; GOVONE, J. S.; MIRANDA, D. M. The influence of visual stimuli in ethnobotanical data collection using the listing task method.

Field Methods. v. 19 (1), p. $76-86,2007$.

MIRANDA, T. M.; HANAZAKI, N. Conhecimento e uso de recursos vegetais de restinga por comunidades das ilhas do Cardoso (SP) e de Santa Catarina (SC), Brasil. Acta Botanica Brasilica, v. 22, p. 203-215, 2008.

MOREIRA, V. M. L. Índios no Brasil: marginalização social e exclusão. Diálogos Latinoamericano, v. 3, p. 87-113, 2001.

ODUM, E. P.; BARRETT, G. W. Fundamentos de Ecologia. 1. ed. São Paulo: Cengage Learning, 2008. 612 p.

PRADO, A. C. C.; RANGEL, E. B.; SOUSA, H. C.; MESSIAS, M. C. T. B. Etnobotânica como subsídio à gestão socioambiental de uma unidade de conservação de uso sustentável. Rodriguésia, 70: e02032017. 2019. Disponível em: < http://dx.doi.org/10.1590/21757860201970019>. Acesso em: 30 set. 2020.

ROLSTON, H. From Beauty to Duty: Aesthetics of Nature and Environmental Ethics. In: BERLEANT, A. Environment and the Arts: Perspectives on Environmental Aesthetics 127-141. Aldershot Hampshire: Ashgate Publishing, 2002. p. 127-141.

RICHARDSON, D.M.; PYSEK P.; REJMANEK, M.; BARBOUR, M.G.; PANETTA, D.; WEST, C.J. Naturalization and invasion of alien plants: concepts and definitions. Biodiversity Research, v. 6, p. 93-107, 2000.

RYAN, J. C. Botanical memory: Exploring emotional recollections of native flora in the Southwest of Western Australia. Emotion, Space and Society, v. 8, p. 27-38, 2012.

SALATINO, A. Nós e as plantas: ontem e hoje. Revista Brasileira de Botânica, v. 24, n. 4, p. 483-490, 2001.

SALATINO, A.; BUCKERIDGE, M. Mas de que te serve sabre botânica? Estudos avançados, v. 30, n. 87, p. 177-196, 2016.

SILVA, V. A.; NASCIMENTO, V. T.; SOLDATI, G. T.; MEDEIROS, M. F. T.; ALBUQUERQUE, U. P. Técnicas para análise de dados etnobiológicos. In: 
ALBUQUERQUE, U. P.; LUCENA, R. F. P.; FERNANDES, L. V. (org.). Métodos e técnicas na pesquisa etnobiológica e etnoecológica. Recife: NUPPEA, 2010. p. 189-206.

TROPICOS.ORG. MISSOURI BOTANICAL GARDEN. Disponível em: http://www.tropicos.org. Acesso em: 30 set 2020.

ULRICH, RS. View through a window may influence recovery from surgery. Science, v. 224, n. 4647, p. 420-421, 1984.

YIN, R. K. Pesquisa qualitativa do início ao fim. 1. ed. Porto Alegre: Penso, 2016. 336 p.

ZILLER, S. R. Plantas exóticas invasoras: a ameaça da contaminação biológica. Revista Ciência Hoje, v. 30, n. 178, p. 77-79, 2001. 